\title{
The Applied Analysis of the Flipped Classroom Teaching Mode in College English Teaching
}

\author{
Shubo Liu \\ School of Foreign Languages, Jilin Agricultural University, Changchun, 130118, China
}

Keywords: Flipped Classroom Teaching Mode, College English, Connotation, Strategy.

\begin{abstract}
The importance of English learning for students' development is self-evident, but the traditional teaching mode has been difficult to adapt to the students' development needs in the current practical teaching process, a new type of teaching mode emerge on the basis of this objective, this mode uses modern network video as a carrier, which helps students to cultivate comprehensive cultural literacy and English comprehensive application ability, and meet the needs of contemporary higher education. In the following, we will introduce the teaching mode of the flipped classroom specifically, and analyze its importance and necessity, so as to put forward the concrete implementation strategy and promote the development of college English teaching.
\end{abstract}

\section{Introduction}

At present, with the deepening of educational reform, colleges and universities in order to better achieve the objective of education and teaching, the traditional teaching mode has been gradually replaced by a new teaching way, and "flipped classroom" as a new way of education, meantime the advanced information technology are integrated, it is popular with teachers and students naturally, flipped classroom is applied in college English teaching, which conforms to psychological needs of students, meanwhile ensure the teaching effect by doing half the work.

\section{Connotation of the Flipped Classroom}

Flipped classroom subverts traditional teaching ideas and mode, so that students become the subject of education and teaching, the teacher has become the leader, therefore, it can also be called inverted classroom. The teachers make the courseware into the relevant video in the teaching process, and integrate the key and difficult points of knowledge tactfully; meanwhile students can also use the teaching video to carry out self-preview and learning, in order to achieve the rapid transmission of knowledge. Besides, students can do online test after the self-learning, thus check absorption and mastery situation of knowledge for themselves, and then specifically study based on that. The implementation of the teaching mode make teachers and students better exchange and discuss, the teachers can also be effectively answer the puzzles for students, It can be seen that this teaching mode provide teachers and students with platform that shares resources, express their views, exchange and cooperate, independently learn and explore, compared with the traditional teaching methods, the initiatives of teachers and students are higher, learning and teaching are more free and autonomous, meanwhile the information technology as the media spread knowledge, which also reflects the modern education advance with the times.

The importance and necessity of applying the Flipped Classroom in College English Teaching

1. The key to solve the difficulties in English education currently. The traditional teaching modes are restricted and influenced by the teaching space, time and other factors, so that classroom teaching can only solve some problems or the general problems that most students pay attention to, thus omitting and ignoring some key points and difficult points, which lead to the gloomy teaching effect. Therefore, the reform of teaching means is an inevitable trend. Moreover, the current social development is changing, college students in order to get a good development, it is necessary to expand thinking, vision and knowledge, however, the teacher as the main body in the previous teaching, 
that was what the teacher taught, what students learned, so it is difficult for students to break, and confined by the "standard answer", cause students have been passive to receive knowledge, learning interest is not high, it is difficult to achieve learning objective. It can be seen that abandon the previous injection and cramming method, new type of teaching modes are used to drive the teaching atmosphere, so that students' easy and pleasant learning is the demand for modern teaching. Moreover, English teachers rely too much on modern information technology in the teaching, which make courseware teaching gradually replace the teachers' teaching, and it will lead to omitting of some key knowledge, the teaching results caused by this teaching mode can be imagined. In summary, it is of great significance to introduce the flipped classroom teaching mode in college English teaching.

2. The Obvious Advantages of Applying Flipped Classroom Teaching Mode in College English Teaching.

First, the flipped classroom teaching mode advocates the "learning before teaching", which will help students to develop their own learning ability. The process of general learning is the process of knowledge transmission and absorption. The previous teaching focuses on the learning before teaching, so that students' problems cannot be solved immediately, thus delaying the internalization of knowledge, and cause learning results to be dissatisfactory. But flipped classroom teaching mode can make up for the above problems, students can learn their own clear questions, and then attend a lecture with the problem and master the key and difficult knowledge. It can be said that flipped classroom is the opportunity of developing college English teaching. The effective application of the flipped classroom is conducive to promote the reform and upgrading of teaching methods and teaching content, promote the college English teaching more in line with the actual needs and development of students, and actively and effectively explore for the college English teaching reform. This process can also cultivate students' ability of autonomous learning, students are constantly exploring their own potential and advantages in the learning course of flipped classroom, so as to effectively improve the efficiency and quality of their English learning and lay the foundation for the following teaching.

Second, the flipped classroom teaching mode can invert the role of teachers and students, and then improve efficiency and effect of classroom. In the past, teachers are the main body of teaching, it is difficult to consider each student's acceptance ability and basic level in teaching, teaching effect is difficult to achieve optimization naturally. However, the flipped classroom can fully consider the individual differences of students, the individual guidance and online learning can effectively enhance the classroom function to meet the demands for efficient classroom. At the same time, in the flipped classroom teaching mode, the role of teachers and students have changed, which make the teacher no longer read according to the book, and become a teaching guide to help students solve problems, correct. Students are no longer passive to accept the knowledge, and become the master of learning, so that students can be well carry out self-exploration and learning, and obtain a sense of accomplishment, satisfaction and self-confidence from it.

Third, the flipped classroom teaching mode can cultivate new teacher-student relationship and create a diversified communication mechanism. The traditional teaching is taught by the teacher, students listen, students thinking are bound to confined, confusion and question are also cannot be resolved, naturally it is difficult to carry out innovation and practice debate, it is unable to meet the development needs of students. But the flipped classroom can achieve the interaction between teachers and students, and the form multi-dimensional three-dimensional communication mechanism, which not only increased the emotional exchange of teachers and students, but also increased the interaction, it also has a positive role in promoting students' coordination ability, problem-solving skills, communication skills, debate ability, inquiry ability and the thinking ability development . And the status of teachers and students is equal in this mode, it is also significant to cultivate the inquiry spirit and anti-pressure ability of the students, "teaching and learning promote each other" teaching state is formed in the long run.

Fourth, the flipped classroom teaching mode can achieve configuration optimization and resource integration. The distributions of educational resources are uneven influenced by regional and teaching difference factors, but the flipped classroom is the integration of information products. In English 
teaching, through the creation of micro-video, the high quality integration of educational resources in different countries can be realized, make the regional cultural differences even at the same time, but also allow students to enjoy high quality resources, fair education will truly reflect. The demands that college students require various English resources are very strong in the learning process, because only the rational use of advanced English materials and methods can achieve scientific and effective learning. Through the rational use of flipped classroom, a wide range of English learning resources are amassed and integrated, and then provide a large number of English learning for students to learn. Teachers can reasonably select relevant English materials based on comprehensively master the learning level and learning needs of students in class, and these micro-videos are played for students, help students learn content and knowledge that they lack, and ultimately promote students to achieve a leap in English learning through a large number of learning.

To sum up, whether it is based on the reasons of contemporary education itself or the advantage of flipped classroom itself, it is of great practical significance to promote flipped teaching model in college English teaching, it plays a decisive role in the success or failure for college English teaching.

\section{The Applied Strategies of Flipped Classroom in College English Teaching}

We have done a careful elaboration for necessity of application of flipped classroom teaching model in the college English teaching above, but in order to maximize its effectiveness, it is necessary to master the application art, including the following aspects:

1. Use a sense of humor. When playing micro video courseware, the teacher must explain and assist by the next, and pay attention to the application of humorous language during the period, meanwhile introduce some relevant context and story, on this account the classroom teaching atmosphere are activated, and attract the attention of students, promote the memory and mastery of knowledge. But when choosing humorous elements, it is necessary to consider the classroom content, make the two associated, besides, the applied time should be paid attention to, thus achieving the teaching objectives. College English teaching should not only pay attention to good professionalism, but also fully stimulate the learning enthusiasm and imitative of students through various ways, the rational use of micro video can achieve this effect in the actual teaching process. Micro video can convey a certain number of knowledge points in a short time, these knowledge points can be reasonably used in a small story or plot, many storyline has a good sense of humor and entertainment, by playing this kind of micro-video for the students, which can effectively attract the students' attention, and effectively stimulate students' learning enthusiasm and imitative. And this kind of entertaining learning can promote students to learn the knowledge point effectively; this process will have a subtle role for the students, prompting the students continually accumulate English words phrases and related grammatical knowledge in the long learning process, and ultimately make students continue to improve their English level and English skills.

2. Grasp the length of micro video. The length of the video usually should be controlled in 10 to 15 minutes, so that it has a complete knowledge structure, videos are made in accordance with the number of knowledge points, ensure that each video includes about two knowledge points, besides, pay attention to the explanation degree and its video independence. The content of micro video content should not be too much, because in order to fully ensure enthusiasm that students learn micro video, the length of micro video need to be controlled. If you add a lot of knowledge and content in a micro video, it is easy for students to lose enthusiasm in the long learning process. So when using micro video to implement English teaching, teachers must reasonably master the length of micro video. Generally speaking, one or two knowledge points can be added in a micro video, which not only conducive to keep students' learning enthusiasm, but also can make full use of micro video time to fully explain the knowledge points, thus promoting students' understanding and master, so that the efficiency and quality of students can be greatly improved by micro video learning, it is conducive to students firmly grasp a certain number of knowledge points in the short classroom learning process, and then through 
a certain period of time accumulation, it can help students significantly improve their own English learning level and ability.

3. Add notes. When teachers playing the micro video, they should add notes and explanation timely, and then students can easily understand the content of the video, meanwhile clear the difficulty sentence and vocabulary. The note can be a supplement to the missing knowledge and can be conversion of the sentence form, so that students can know and understand the knowledge point when they are learning, and achieve the purpose of mastering the teaching contents. Because students' learning ability and learning level are different, and the students' English foundation is difficult to be unified, so in order to take care of students' learning needs in the class, teachers also actively add the contents of the notes in the process of adapting to micro video, it can help students quickly grasp the word or grammar knowledge that they do not understand. When teachers add notes, they should pay attention to key words, sentence patterns and grammar knowledge and implement a comprehensive explanation, the teacher's notes can not only the deep explain original deeply, but also expand and extend on this basis to a certain extent, the learning content of classroom as a starting point and introduce a large number of English knowledge for students, which can not only increase the students' learning enthusiasm, but also can help students significantly improve their English literacy and knowledge in the classroom learning process, and ultimately promote the effective improvement of students' comprehensive ability.

In the following, we will take examples to introduce the application of flipped classroom teaching mode. The first step is micro video production, such as explaining "Friendship" (class), the teacher first produced 15-20 minutes of teaching micro video, the theme of the article is "All the Cabbie Had Was a Letter", after introduce the "A true friend is one soul in two bodies in the video." explain the important phrases and words in the text, such as go by, shrug, urge, shake, estimate, reply to, look up, etc., and extend the relevant knowledge points, such as the introducing synonyms, etc., the length is controlled about 6 minutes, and help students clear the reading barrier. The author of the article and its related achievements are introduced, and display the photo the time is about 1 minute. Then the text reading recordings or related animation videos are played, the time is about 3 to 4 minutes, guide students to pronounce and simulate tone. Finally, difficult sentence, grammar, vocabulary, comprehensive training and testing are made; the time is about 4 minutes, and provides a rapid self-testing platform for students. The above micro video integrate online self-test, film and television teaching, PPT explanation in one, and it has a short features, can effectively stimulate students' learning enthusiasm, meanwhile the attention of students are attracted, learning tasks will naturally carry out driven by curiosity. The second step is the interaction between teachers and students, in the learning process, the students have doubts about the knowledge points and it is natural phenomenon, through online self-test, students and teachers are able to accurately find the problem, and then explain specifically. During this period, the teacher can allows students to make group learning and discussion, for instance, the members tell the understanding the friendship or related content, which will create a relaxed language environment, and students form the noble personality shaping. During the students' exchange and discussion, the teacher can give advice by the side to help students better express oral English. Under the effect of this teaching mode, the students' oral English ability, communicative competence, comprehensive application ability and mastery of knowledge will be greatly improved, which is conducive to achieve the teaching objective as soon as possible.

\section{Conclusion}

We understand that the effects of current college English teaching are not optimistic through the above discussion, in order to obtain substantial progress; the traditional teaching thinking and methods must be abandoned and teaching methods and ideas are constantly innovated. As a new type of teaching method, the flipped classroom teaching mode does not only conform to the students' demand for advanced information technology, which can meet the requirements of English teaching objectives 
of college students. Therefore, the flipped classroom teaching mode is applied in contemporary college English teaching, which is both feasible and necessary.

\section{Acknowledgements}

The paper is supported by research program sponsored by Jilin Social Science Foundation, Project Number: 2016wy16

\section{References}

[1]. Wang Yugong. The feasibility analysis on "flipped classroom" mode in the application of college English teaching based on micro course [J], Journal of Jiamusi Vocational Institute, 2016 (6).

[2]. Huang Min. The feasibility analysis on "flipped classroom" mode in the application of college English teaching based on micro course [J], Time Education, 2016 (7): 2-3.

[3]. Li Weiwei. The feasibility analysis on "flipped classroom" mode in the application of college English teaching based on micro course [J], English on Campus, (8) : 2016-13.

[4]. Chen Juan. The feasibility analysis on "flipped classroom" mode in the application of college English teaching based on micro course [J], Journal of Chifeng University: Teaching \& Research in Writing, 2016 (5) : 39-39.

[5]. Zhao Liang. The feasibility analysis on "flipped classroom" mode in the application of college English teaching based on micro course [J], Journal of quality education in the west and 2016, 2 (16): 44-44. 